\title{
COMMUNITY-BASED ECOSYSTEM APPROACH IN CONTROLLING DENGUE HEMORRHAGIC FEVER VECTOR
}

\author{
Lilik Zuhriyah ${ }^{1)}$, PM Laksono²), Tri Baskoro TS3), Hari Kusnanto4) \\ 1)Department of Public Health and Preventive Medicine, Faculty of \\ Medicine, University of Brawijaya \\ 2)Faculty of Cultural Science, Gadjah Mada University \\ 3)Department of Parasitology, Faculty of Medicine, \\ Gadjah Mada University \\ 4)Department of Public Health, Faculty of Medicine, \\ Gadjah Mada University
}

\begin{abstract}
BACKGROUND: Dengue hemorrhagic fever vector control needs to involve the community as dengue is a bio-anthroposocial disease. However, vector control has been so far implemented separately from the community involvement. It is therefore necessary to integrate the vector control into an ecosystem approach. This study aimed to determine the effect of ecosystem approach in reducing the density of dengue vector in urban areas.

SUBJECT AND METHODS: A community-based controlled trial was conducted in six neighborhoods and four elementary schools in Malang, from June 2013 to December 2015. These communities were assigned into 3 groups: (1) Ecosystem I group; (2) Ecosystem II group; and (3) Control group. The independent variable under study was the ecosystem approach comprising larva surveillance, ovitrap, and inorganic waste management. This ecosystem was preceded by an in-depth community need assessment. This ecosystem was implemented over 4 months. The dependent variables included Density Index, Maya Index, and mean number of eggs per ovitrap. The data were analyzed with 3 weekly moving average charts, Kruskal-Wallis test and Mann-Whitney Test.

RESULTS: The Density Index was lower both in ecosystem I group and ecosystem II group than in the control group, and it was statistically significant $(\mathrm{p}=0.002)$. The difference in Density Index between the ecosystem I group and ecosystem II group was not statistically significant ( $>0.05)$. The Maya Index $(\mathrm{p}=0.287)$ and mean number of eggs per ovitrap $(p=0.851)$ were not statistically different among the 3 groups. All of the mosquito larvae hatched from ovitrap eggs are Aedes.

CONCLUSION: The ecosystem approach with mosquito larva surveillance, ovitrap application, and inorganic waste management, preceded by indepth need assessment, can decrease the density of Aedes mosquito. The ecosystem approach can improve community participation.
\end{abstract}

Keywords: dengue hemorrhagic fever, ecosystem approach, larva surveillance, ovitrap, Density Index, Maya Index 